\title{
Trust and knowledge creation: The moderating effects of legal inadequacy
}

\begin{abstract}
Purpose This study aims to empirically investigate the effects of competence and goodwill trust on knowledge creation and the moderating effects of legal inadequacy on those relationships.

Design/methodology/approach A questionnaire survey was used to collect data from 196 research and development alliances in China. Hierarchical moderated regression was used to test the research hypotheses.

Findings We find that competence trust has a positive and linear relationship with knowledge creation while goodwill trust has an inverted U-shaped relationship with it. The results also reveal that the inverted U-shaped relationship between goodwill trust and knowledge creation is stronger when legal inadequacy is high, while the impact of competence trust on knowledge creation is not influenced by legal inadequacy.

Originality/value The findings provide insights into the distinctive effects of competence and goodwill trust on knowledge creation in partnerships, deepening current understandings of the bright and dark sides of inter-firm trust. This study also clarifies the influences of legal inadequacy on the effectiveness of competence and goodwill trust, which enhances existing knowledge about the impact of legal systems on the relationships between inter-firm trust and knoweldge management.
\end{abstract}

Keywords: competence trust; goodwill trust; knowledge creation; legal inadequacy

Article Classification: Research paper 


\section{Introduction}

A growing body of studies finds that external knowledge sources, such as research and development (R\&D) alliances, play critical roles for firms to create new knowledge and gain competitive advantages (Wang et al., 2011; Shu et al., 2012; Ramirez et al., 2012; Sheng et al., 2013; Lloria and Peris-Ortiz, 2014; Zhang et al., 2016). Inter-firm partnerships may suffer from various opportunistic risks, therefore trust is considered as an important informal governance mechanism to ensure the success of knowledge absorption and creation for firms in $R \& D$ alliances (Yeung et al., 2009; Shu at al., 2012; Kuo, 2013). To develop technological innovations, firms must create new knowledge together with R\&D alliance partners (Un and Asakawa, 2015). Inter-firm trust can decrease transaction costs in R\&D alliances (Faems et al., 2008) and hence partners are more willing to collaborate, which helps a firm to develop not only new knowledge but also new applications of existing knowledge (Li et al., 2010; Cai et al., 2010; Zhou et al., 2014).

Researchers argue that trust is a multidimensional concept (Mayer et al., 1995; Kuo, 2013). A firm may trust a partner in certain aspects and distrust the same partner in other areas (Jeffries and Reed, 2000). Competence trust refers to the positive expectations about a partner's ability to perform according to an agreement, whereas goodwill trust is the partner's intentions to fulfill its role in the relationship (Lui and Ngo, 2004; Faems et al., 2008). The two types of trust reflect different expectations and play different roles in partnerships (Levin and Cross, 2004; Lui and Ngo, 2004). For example, a certain level of goodwill trust implies a reduced threat of opportunism, such as knowledge appropriation risks, but competence trust does not (Lui and Ngo, 2004). Therefore, distinguishing between goodwill and competence trust can lead to a holistic understanding on how to manage knowledge creation in R\&D alliances using informal governance mechanisms (Connelly et al., 2015).

A knowledge-based view of firm is used to examine the effects of inter-firm trust on knowledge creation (Nonaka, 1994). Knowledge is the most strategically significant resource of a firm, and a firm can be considered as mechanisms that facilitate knowledge creation (Grant, 1996). Knowledge creation is a dynamic and interactive process that leads to a growth in knowledge stock (Smith et al., 2005; Samaddar and Kadiyala, 2006). This process involves conversion and integration of various sources of knowledge, which is facilitated by trust (Nonaka, 1994; Zahra and George, 2002). 
Although extant research has noted that transition economies represent an institutional environment characterized by a lack of well-established legal frameworks, with few exceptions (e.g., Sheng et al., 2013; Zhou and Poppo, 2010), researchers generally overlook the impact of legal systems on the roles of trust. Meanwhile, empirical evidence indicates that legal systems influence inter-organizational learning and knowledge creation (Zhou and Poppo, 2010; Cai et al., 2010; Zhang et al., 2017). In particular, inadequate legal systems cannot impose severe punishments on unlawful or unethical competitive behaviors such as contract violations, copyright piracy, and counterfeiting, and make it difficult for firms to protect intellectual property rights and other business interests (Zhou and Poppo, 2010; Zhou et al., 2014). Unreliable and unstable legal systems may increase collaboration uncertainties and risks, which reduce firms' anticipation of the value of knowledge creation (Hemmert, et al., 2016; Zhang et al., 2017). Legal inadequacy thus drives firms to rely on trust to resolve their disputes and gain institutional supports, and hence influences the effectiveness of trust (Cai et al., 2010; Sheng et al., 2013; Kuo, 2013). Therefore, an institutional contingency perspective provides an important lens to examine how inter-firm trust affects knowledge creation in R\&D alliances (Cai et al., 2010; Jiang et al., 2013; Hemmert, et al., 2016).

Drawing on the knowledge-based view and institutional theory, this study seeks to empirically investigate the distinctive effects of competence and goodwill trust on knowledge creation and the impacts of legal inadequacy. This study addresses two research questions. First, what are the effects of competence and goodwill trust on knowledge creation? Second, how does legal inadequacy moderate such effects?

\section{Theoretical background and research hypotheses}

\subsection{Competence and goodwill trust}

Trust can be defined as the "willingness of a party to be vulnerable to the actions of another party based on the expectation that the other will perform a particular action important to the trustor, irrespective of the ability to monitor or control that other party" (Mayer et al., 1995:712). It reflects a firm's expectation that alliance partners can be relied on to fulfil obligations and behave in a predictable manner, and the firm's confidence in partners' reliability and integrity (Schoorman et al., 2007; Kuo, 2013). Trust has been viewed as a relational lubricant and a substitute for formal governance mechanisms in alliances (Ireland and Webb, 2007; Faems et al., 2008). It 
can promote collaboration, dispute resolution, and the sharing of risks and costs associated with exploring new opportunities (Molina-Morales et al., 2011).

As a state of mind about an aspect of a relationship, a firm has different reasons to trust an alliance partner (Mayer et al., 1995; Levin and Cross, 2004). Competence and goodwill have been identified as two dimensions that explain a major portion of trustworthiness (Das and Teng, 2001; Faems et al., 2008). Competence trust stems from the positive expectation that a given partner has the managerial and technical capabilities and skills that enable the partner to perform specific tasks and to have influences within some specific domains (Das and Teng, 2001). It emphasizes the knowledge aspects and rational evaluations of a partner's ability to carry out obligations (Jiang et al., 2013). A partner is perceived as competent and capable if it can provide adequate rational grounds or evidence (Connelly et al., 2015). In contrast, goodwill trust is rooted in perceptions about a partner's motives, honesty, and integrity, and is characterized by benevolence, open commitment, and vulnerability (Yeung et al., 2009). Goodwill trust arises from repeated interactions and the alignment of values and motives between partners (Lui and Ngo, 2004). It exists when a firm believes partners are willing to act in ways exceeding stipulated contractual agreements (Ireland and Webb, 2007). Different values and motives between partners can undermine confidence and erode goodwill trust (Jeffries and Reed, 2000). Competence and goodwill trust are different and may coexist in partnerships (Das and Teng, 2001; Levin and Cross, 2004). They are created and sustained through different processes. For example, competence trust can be developed based on public information collected from markets, while goodwill trust usually arises from ongoing interactions (Lui and Ngo, 2004).

Although a firm rarely depends on only one type of trust to manage partnerships, with few exceptions (Levin and Cross, 2004; Jiang et al., 2013), previous studies have typically employed unidimensional or global measures to empirically investigate the effects of inter-firm trust (e.g., Yeung et al., 2009; Cai et al., 2010; Molina-Morales et al., 2011; Hemmert et al., 2016). This approach ignores the complex nature of interfirm trust, leading to mixed empirical findings. For examples, researchers have found both linear (Wang et al., 2011; Shu et al., 2012) and quadratic (Villena et al., 2011; Zhou et al., 2014) relationships between trust and inter-organizational learning and innovation. Researchers also argue that inter-firm trust may lead to relational lock-in and over-embeddedness in alliances, which restrict the flow of novel information and 
ideas and impede knowledge creation (Molina-Morales et al., 2011; Villena et al., 2011; Zhou et al. 2014). Hence, the distinctive effects of competence and goodwill trust in an alliance on knowledge creation call for further investigation.

\subsection{Knowledge creation}

Knowledge creation can be defined as the extent to which a firm successfully develops new technology, product, and market knowledge by collaborating with partners (Samaddar and Kadiyala, 2006). It lies at the heart of a firm's core capabilities and is critical to the long-term success of the firm (Ramirez et al., 2012; Lloria and Peris-Ortiz, 2014). With the increasing pace of market changes, it becomes difficult for firms to create new knowledge using internal resources alone (Wang et al., 2011). Hence, they turn to partnerships to develop new knowledge (Smith et al., 2005; Schilke and Goerzen, 2010). R\&D alliances can expose firms to different knowledge and perspectives and open new sources of ideas or expertise, which promote them to consider different alternatives and increase their creativity and willingness to explore new ideas and develop new knowledge (Robson et al., 2008). Partners are more likely to get more chances to observe each other's behaviors and to work together to solve problems, which facilitate knowledge combination (Zahra and George, 2002; Lui and Ngo, 2004). External knowledge constitutes an important input for a firm's knowledge conversions (Ramirez et al., 2012). By integrating and combining the acquired external knowledge regarding technologies, products, and markets into its own knowledge base, new knowledge is created (Zahra and George, 2002; Zhou et al. 2014).

\subsection{Legal inadequacy}

Legal inadequacy refers to the extent to which legal systems cannot provide firms with sufficient protection for their intellectual property rights and other business interests (Sheng et al., 2013). In emerging markets such as China, firms may suffer from relatively underdeveloped legal systems such as insufficient laws, ineffective legislation, and regulatory loopholes (Zhang et al., 2017). In addition, the China's legal systems lack transparency and consistency because the regulations and laws formulated by local governments may change frequently (Zhou and Poppo, 2010). Moreover, the law enforceability of the China's legal systems is also low because of the lack of judicial independence (Zhou and Poppo, 2010; Zhang et al., 2016). Hence, court decisions may not be effectively implemented and a firm may not be able to get their compensations for a variety of reasons. Therefore, firms often face high costs 
when they resolve conflict or problems through judiciary means in China (Cai et al., 2010; Zhang et al., 2017).

It should be noted that the development level of the legal systems in different provinces and cities of China is far from balanced. In the developed areas of China, the transparency of law enforcement is better, and firms' consciousness of protecting themselves through legal means is also stronger (Ang and Jia, 2014). In contrast, inadequate legal protection and weak law enforceability are prevalent problems in the under-developed regions of China, and the available legal services are also extremely scarce. Meanwhile, the judiciary and court systems are more corrupted in the underdeveloped areas (Ang and Jia, 2014). Therefore, Chinese firms face various levels of legal inadequacy (Sheng et al., 2013; Zhou and Poppo, 2010).

\subsection{Research hypotheses}

\subsubsection{The impact of competence trust on knowledge creation}

Competence trust indicates that a firm believes its partner is capable of fulfilling its roles and responsibilities, and can find the best solutions for both current and new problems as they emerge (Das and Teng, 2001; Faems et al., 2008). Competence trust can promote knowledge creation in two ways. First, with low perceived performance risks, alliance members have positive expectations of collaborative $R \& D$ projects and a great inspiration to invest in physical and human resources for collaborative knowledge development, even when confronting with predicaments (Levin and Cross, 2004). Hence, competence trust brings insurance over the quality, relevance, and timeliness of knowledge flows within a R\&D alliance, enabling a firm to create novel knowledge unrelated to its own knowledge domains (Molina-Morales et al., 2011).

Second, when a firm feels confident about the managerial and technical capabilities of a partner, the firm will reduce the costs and time of verifying the validity and usefulness of the knowledge that is outside its expertise (Jiang et al., 2013; Kuo, 2013). Competence trust thus decreases the need for repeated explanation and facilitates less frequent but productive interactions (Das and Teng, 2001). A firm is more likely to listen to and learn from partners' suggestions, and take actions accordingly. The speed, depth, and width of knowledge development are also improved, which enable a firm to fully seize the benefits of integrating partners' knowledge and allow the firm to apply the partners' competence and resources for knowledge creation (Smith et al., 2005;Un and Asakawa, 2015). Therefore, we propose the following hypothesis. 
H1. There is a positive and linear relationship between competence trust and knowledge creation.

\subsubsection{The impact of goodwill trust on knowledge creation}

Goodwill trust enables $R \& D$ alliance partners to create knowledge together (Zahra and George, 2002). Goodwill trust not only leads to a working environment with open communication, team spirit, and cooperation, but also generates incentives, reciprocity, and solidarity that are conductive for collaborative knowledge development within a R\&D alliance (Doney et al., 1998; Jiang et al., 2013). It ensures alliance partners that their knowledge and resources will be used for good purposes and the relationship-specific assets developed during the partnership will be protected (Poppo et al., 2008). Furthermore, a certain level of goodwill trust can establish a basis for intimacy, predictability, and reliability among partners, and hence firms become more open and receptive of new knowledge and more willing to explore new opportunities together (Molina-Morales et al., 2011; Villena et al., 2011). Knowledge creation can greatly benefit from such diverse and novel inputs (Grant, 1996; Samaddar and Kadiyala, 2006).

However, the impact of goodwill trust is unlikely to remain linear and the positive effects may decline after it reaches a certain level (Villena et al., 2011; Zhou et al., 2014). To develop and maintain goodwill trust, a firm must constantly invest resources in an alliance partnership (Molina-Morales et al., 2011). Therefore, the costs of maintaining and sustaining goodwill trust with partners may surpass the benefits it brings to the firm (Villena et al., 2011). Excessive levels of goodwill trust may reduce a firm's efforts in monitoring, which can create occasions for opportunistic behaviors (Molina-Morales et al., 2011; Zhou et al., 2014). Too much goodwill trust may also restrain a firm's motivation to critically evaluate acquired knowledge, leading to the problem of insufficient communication (Ireland and Webb, 2007). Alliance partners may take for granted in knowing each other's ideas and plans, and fail to discover changes in business environments (Mayer et al., 1995). In addition, goodwill trust indicates greater emotional bonds with alliance partners and the firm may be trapped in unhealthy relationships (Poppo et al., 2008; Robson et al., 2008). The firm may be impeded from acquiring new information and knowledge from other sources and blind obedience may arise (Molina-Morales et al, 2011; Zhou et al., 2014). Consequently, we argue that there is an inflection point in the relationship between goodwill trust and knowledge creation, after which goodwill trust negatively 
influences knowledge creation. Therefore, we propose the following hypothesis.

H2. There is an inverted U-shaped relationship between goodwill trust and knowledge creation.

\subsubsection{The moderating effects of legal inadequacy}

High levels of legal inadequacy indicate that there is a lack of rule of law and it is difficult or expensive to follow legal processes to protect business interests and enforce contracts, which increase exchange hazard (Zhou and Poppo, 2010; Hemmert, et al., 2016). Chinese culture is characterized by high power distance and uncertainty avoidance, and hence managers rely on authorities or experts to determine the quality and value of knowledge and tackle ambiguities and risks (Hofstede et al., 2010). Competence trust can be formed based on public information about partners' reputation and resources, such as $R \& D$ investments, patents, copyrights, and number of engineers and scientists (Mayer et al., 1995; Das and Teng, 2001). It helps firms to identify expertise and build relationships with experts, which reduce uncertainties and threats caused by inadequate legal systems (Doney et al., 1998; Jiang et al. 2013). When there is a lack of laws and regulations to govern collaboration, firms depend more on competence trust to evaluate and assess partners' capabilities to meet obligations and to guarantee the value of the knowledge created together with the partners (Doney et al., 1998). Hence, competence trust plays a more significant role in learning from partners and creating new knowledge when legal systems are weak and inefficient. Therefore, we propose the following hypothesis.

H3. The positive effect of competence trust on knowledge creation is stronger when legal inadequacy is high.

Legal inadequacy also strengthens the positive effect of goodwill trust on knowledge creation when goodwill trust is at relatively low or moderate levels. Chinese culture emphasizes collectivism and hence managers tend to maintain harmony and use personal ties or guanxi to coordinate transactions (Hofstede et al., 2010). High levels of legal inadequacy may increase dysfunctional competition (Zhang et al., 2017). For example, a partner may not contribute to knowledge creation, claim an unfair share of the created value, or leak the knowledge to parties outside an alliance (Ireland and Webb, 2007). Certain levels of goodwill trust can deal with the threats of weak legal systems by ensuring that a partner's behaviors are predictable and his/her intention is benevolent (Doney et al., 1998). Alliance partners are also more likely to become in-groups and make relationship-specific investments 
(Hofstede et al., 2010). Hence, when legal inadequacy is high, certain levels of goodwill trust play a more important role in reducing uncertainties and risks in collaboration and hence are more important for knowledge creation (Zhou and Poppo, 2010; Wang et al., 2011).

Legal inadequacy may also amplify the negative impact of goodwill trust on knowledge creation by aggravating collective blindness and partners' opportunistic behaviors when goodwill trust is at high levels (Villena et al., 2011; Zhou et al., 2014). In a collectivist and long-term oriented culture, managers may subordinate a firm's performance for the alliance's future potential benefits and believe the relationship is more important than profits, and their opinions are significantly influenced by partners (Hofstede et al., 2010; Lui and Ngo, 2012). High levels of legal inadequacy make it costly for firms to adjust alliances through contracts and hence they are more likely to suffer from undesired rigidity, inertia, and relational lock-in (Cai et al., 2010). Therefore, too much goodwill trust will lead to overdependence of alliance partners and firms may become too homogeneous in their routines and mental models, which constrain knowledge creation (Ireland and Webb, 2007). In addition, the possibility that a partner behaves opportunistically is determined by the calculation of the benefits of cheating and the costs of being caught (Doney et al., 1998; Yeung et al., 2009). Managers may be reluctant to monitor collaboration and audit partners' performance frequently and critically when there are high levels of goodwill trust, which reduce the possibility of detecting opportunism in alliances (Molina-Morales et al., 2011; Faems et al., 2008). High levels of legal inadequacy indicate that there is a lack of law to protect business interests and investments and it is costly to enforce contracts, which decrease the costs of opportunistic behaviors (Zhou and Poppo, 2010). Hence, a partner may gain rewards for cheating and legal inadequacy amplifies the dark sides of goodwill trust. Therefore, we propose the following hypothesis.

H4. The inverted U-shaped effect of goodwill trust on knowledge creation is stronger (steeper) when legal inadequacy is high.

\section{Research method}

\subsection{Sampling and data collection}

To test the aforementioned hypotheses, this study used cross-sectional survey data from $196 \mathrm{R} \& \mathrm{D}$ alliances in China. R\&D alliance is defined as the formal contractual relationships among two firms on collaborative new product and/or 
technology development (Schilke and Goerzen, 2010; Jiang et al., 2013). Researchers argue that a firm's partners are different in their characteristics and trustworthiness and thus the firm develops different levels of trust with partners across different R\&D alliances (Schoorman et al., 2007). Hence, R\&D alliance was used as the unit of analysis of this study.

The study used a sample of 800 firms selected randomly from government directories of firms in the Hunan, Hubei, Shaanxi, Liaoning, Shanghai, and Guangdong provinces of China. They are located in Central, Northern, Eastern, and Southern China, respectively. Shanghai and Guangdong are two special economic zones in Eastern and Southern China and are among the most developed areas (Zhang et al., 2016). The Hunan, Hubei, Shaanxi, and Liaoning are industrial bases in Central and Northern China, reflecting the average stage of economic development (Wang et al., 2011). Each firm was contacted by telephone to (1) verify that it was currently engaged in at least one R\&D alliance, (2) identify and locate key informants and obtain each informant's contact information, and (3) verify the key informants who were knowledgeable about the firm's management procedures regarding $R \& D$ alliances, and obtain his/her cooperation regarding participation in our study. Based on these responses, we identified 247 firms that had R\&D alliances and were willing to participate in this research.

The English version of the questionnaire was first developed and subsequently translated into Chinese by a professor. The Chinese version was then translated back into English by another professor. Any conflicts were discussed by the researchers until they reached agreement. The research team, which included three professors and three research assistants, conducted five in-depth interviews with senior managers, during which they were asked to verify the relevance and completeness of the questionnaire. From their responses, measurement items were revised to clarify their meanings. A pilot test was then conducted with 28 managers using the Chinese questionnaire.

A face-to-face interview method was used to collect survey data. The research team presented the questionnaires to informants of each firm and collected the surveys after their completion. The research team interviewed one senior manager (i.e., chief executive officer, vice president, or general manager), and one or more middle managers (i.e., R\&D department manager or $R \& D$ project manager) in each firm, according to the number of R\&D alliances identified. Specifically, senior managers 
provided information about legal inadequacy, and middle managers were asked about inter-firm trust, knowledge creation, and collaboration with partners (i.e., behavioral uncertainty, prior ties, long-term orientation, and cooperation duration) in $R \& D$ alliances. Firm age was collected from government directories.

The research team successfully obtained responses from 189 firms and hence the effective response rate is $76.5 \%$. We dropped 34 cases because of excessive missing data. To assess the informants' quality, we asked these respondents to indicate the time (years) they worked for their firms. The means are 6.19 and 5.87 for the senior and middle managers respectively, indicating they were qualified respondents. Of the 155 firms, 131 firms were involved in 1 alliance, 12 firms were involved in 2 alliances, 7 firms were involved in 3 alliances, and 5 firms were involved in 4 alliances. Therefore, the final sample consisted of 196 R\&D alliances. Detailed information on the sample demographics is shown in Table 1.

Insert Table 1 here.

We compared 155 participating and 58 nonparticipating firms on firm age, ownership, and industry using T-tests. All t-statistics are insignificant. Furthermore, we split the final sample into two groups according to the return date. The early-wave group consisted of 110 responses, while the late-wave group, which was received five months later, included 86 responses. T-tests performed on the two groups yield no statistically significant differences on any demographic characteristics. All these analyses suggest that nonresponse bias is not a concern in our study.

We conducted the following tests to rule out the possibility of common method bias. First, we conducted Harman's one-factor test (Podsakoff and Organ, 1986), which loads all perceptual items into an exploratory factor analysis. The first factor accounts for only $21.65 \%$ of the total variance, indicating common method bias is unlikely to be a major concern in our data. Second, we used a method variance (MV) marker test, which uses a scale theoretically unrelated to the constructs in the model as the MV marker variable, which is a proxy for common method variance (Lindell and Whitney, 2001). We used government support, which was measured by a fiveitem scale, as the MV marker and selected the lowest positive correlation $(r=0.010)$ between the MV marker and other variables to adjust for construct correlations and statistical significance. Table 2 shows that none of the significant correlations became insignificant after the adjustment. Therefore, common method bias is not a serious 
concern.

\subsection{Measurement design}

Based on the relevant literature, a survey instrument was designed with modification for the research context. A multiple-item, 5-point Likert-type scale $(1=$ "strongly disagree"; 5= "strongly agree") was used for all constructs. The scales are listed in the Appendix.

Competence trust was measured by four items capturing the positive expectations about partners' capabilities and competence (Lui and Ngo, 2004; Jiang et al., 2013). We measured goodwill trust using three items about the confidence that a firm has in its partner's integrity and good intentions (Schoorman et al., 2007). Following the study by Samaddar and Kadiyala (2006), we measured knowledge creation using three items reflecting the new technological, product, and market knowledge developed through $R \& D$ alliances. Legal inadequacy was measured by four items about the effectiveness and sufficiency of legal and judicial systems based on the studies by Cai et al. (2010) and Sheng et al. (2013).

Firm age, cooperation duration, behavioral uncertainty, prior ties, and long-term orientation were included as control variables in the analysis as they may affect knowledge creation in R\&D alliances. Firm age was measured by the number of years the firm has been in operation. We controlled firm age because established firms often have rich experiences in knowledge creation through $R \& D$ alliances (Schilke and Goerzen, 2010). Cooperation duration refers to the time length of the partnership between partners. Partners in long-lasting alliances may have more time to develop a mutual understanding, which is helpful for knowledge creation (Li et al., 2010). We measured cooperation duration by a single item, i.e., the number of years that both sides have been involved in the alliance partnership.

Behavioral uncertainty occurs when a firm cannot effectively monitor or measure the performance or actions of its partners. As a kind of exchange risk, behavioral uncertainty may impede knowledge transfer among partners. Following Zhou and Poppo (2010), three items assessing the difficulty of evaluating the performance of a partner and the degree to which the partner follows contractual arrangements were used to measure behavioral uncertainty. Prior ties with a partner's network provide the groundwork for alliances (Lui and Ngo, 2012). A good relationship with a partner's network allows a firm to know the partner better and promotes joint knowledge creation among them. Prior ties were measured by four items capturing 
previous collaborative relationships between a firm and the partner's network (Robson et al., 2008). Long-term orientation refers to the expectation of working together in the future held by both of the exchange parties (Lui and Ngo, 2012). It has been found to be positively related to knowledge creation among partners (Poppo et al., 2008). Following Lui and Ngo (2012), five items about the expectation of developing long-term relationships with a partner were used to gauge long-term orientation.

\subsection{Reliability and validity}

The reliability and validity assessments are reported in the Appendix. Reliability was assessed using the Cronbach's alpha and composite reliability (CR). Both Cronbach's alpha (ranging from .73 to .91) and CR (ranging from .85 to .94) values are above .70, demonstrating adequate reliability. We assessed convergent validity using a confirmatory factor analysis (CFA) with structural equation modeling and the average variance extracted (AVE) of each construct (Fornell and Larcker, 1981). The CFA model fits the data satisfactorily $\left(\chi^{2}(278)=415.80\right.$, goodness-of-fit index [GFI] $=.86$, confirmatory fit index $[\mathrm{CFI}]=.93$, incremental fit index $[\mathrm{IFI}]=.93$, and root mean squared error of approximation [RMSEA] $=.06$ ), and all factor loadings (ranging from .70 to .92) are highly significant $(p<.001)$, indicating the convergent validity of the measures. All AVE values are above the recommended value of .50 (ranging from .64 to .76), which also demonstrates adequate convergent validity (Fornell and Larcker, 1981).

We assessed discriminant validity using chi-square difference test and AVE method. We performed chi-square difference tests for all constructs in pairs to determine whether the constrained model (i.e., the correlation of the paired constructs was fixed at 1) is significantly worse than the freely estimated model (i.e., all correlations were estimated freely). All chi-square differences are highly significant (e.g., goodwill trust vs. knowledge creation: $\Delta \chi^{2}(1)=136.60, p<.001$ ), in support of discriminant validity. Table 2 presents the means, standard deviations, and correlations of all constructs used in the study. An examination of Table 2 reveals that the square root of AVE for each construct is higher than the correlations between the focal construct and every other construct, which again supports discriminant validity (Fornell and Larcker, 1981).

Insert Table 2 here. 


\section{Analyses and results}

To mitigate the potential threat of multicollinearity, the independent and moderating variables are mean-centered prior to the formation of quadratic and interaction terms, as recommended by Aiken and West (1991). Furthermore, we calculate variance inflation factors (VIFs) to assess multicollinearity. The largest VIF value is 1.93 , well below the benchmark of 10 , suggesting multicollinearity is not a concern in this study (Aiken and West, 1991).

Hierarchical moderated regression is used to test the hypotheses. We enter the variables into the models in a three-step process: (1) control variables; (2) direct effect variables; and (3) moderating variables. The results presented in Table 3 reveal that the $\mathrm{R}^{2}$ value increases significantly for Model 2 and 3 and that they explain $42 \%$ and $48 \%$ of the total variance in knowledge creation respectively.

Insert Table 3 here.

As shown in Model 2, competence trust significantly affects knowledge creation $(\beta=.29, p<.001)$, and the effect of the quadratic term of competence trust is not significant. Hence, competence trust has a positive and linear effect on knowledge creation, in support of $\mathrm{H} 1$. Results also show that the quadratic term of goodwill trust negatively affects knowledge creation $(\beta=-.16, p<.05)$. Therefore, goodwill trust displays a curvilinear relationship with knowledge creation, which supports H2. Model 3 shows legal inadequacy does not significantly influence competence trust's effect on knowledge creation. Hence, H3 is not supported. The interaction between goodwill trust squared and legal inadequacy is significantly negative $(\beta=-.21, p<.05)$, in support of $\mathrm{H} 4$.

To demonstrate visually the moderating effect of legal inadequacy, we plot the relationship between goodwill trust and knowledge creation for the low and high levels of legal inadequacy. As Figure 1 shows, when goodwill trust is relatively low (left side of the dotted line), knowledge creation increases faster with increasing goodwill trust when legal inadequacy is high. When goodwill trust is relatively high (right side of the dotted line), knowledge creation decreases faster with increasing goodwill trust when legal inadequacy is high. Hence, legal inadequacy strengthens the 
inverted U-shaped effect of goodwill trust on knowledge creation.

Insert Figure 1 here.

\section{Discussion and conclusions}

While literature has emphasized the importance of trust on managing knowledge in partnerships, the mechanisms through which trust affects knowledge creation remain equivocal (Wang et al., 2011; Shu et al., 2012; Villena et al., 2011; Zhou et al., 2014). To deepen the understandings of the roles of inter-firm trust, this study investigates the distinctive effects of goodwill and competence trust on knowledge creation. Using a sample of $R \& D$ alliances in China, we find that competence and goodwill trust play different roles in improving knowledge creation. In particular, competence trust has a positive and linear effect on knowledge creation, which is consistent with the argument that trust facilitates inter-firm knowledge management by promoting collaboration (Wang et al., 2011; Connelly et al., 2015). Hence, competence trust is a good thing that the more the merrier. In contrast, goodwill trust has an inverted U-shaped relationship with knowledge creation, which indicates that a moderate level of goodwill trust is optimal and very strong or weak goodwill trust is detrimental for knowledge creation. Hence, goodwill trust has both bright and dark sides and may be in danger of being either "oversold" or "undersold" (Villena et al., 2011; Zhou et al., 2014). In other words, too much goodwill trust can be as bad as too little and may damage knowledge creation in R\&D alliances. Therefore, competence trust has no negative effects on knowledge creation but high levels of goodwill trust in an alliance may be harmful for collaborative knowledge development.

The findings also reveal that the effect of goodwill trust is contingent on legal inadequacy. Both bright and dark sides of goodwill trust are amplified by legal inadequacy. In underdeveloped legal systems, a moderate level of goodwill trust is the best for knowledge creation in R\&D alliances. Meanwhile, high levels of goodwill trust can lead to lower degrees of knowledge creation and a firm may suffer more from reduced pursuit of new knowledge when legal inadequacy is high. Competence trust indicates that a firm may hold expert power (Mayer et al., 1995) and has the ability to provide or withhold rewards in promoting desired behaviors in partnerships (Ireland and Webb, 2007). Chinese culture has high power distance (Hofstede et al., 
2010) and hence power plays a significant role in managing uncertainties and relationships (Yeung et al., 2009). Power can provide legitimacy and stability to partnerships and influence partners' decisions by creating positive or negative consequences. Hence, a firm may use power, instead of competence trust, to tackle the risks and threats associated with legal inadequacy when managing $R \& D$ alliances in China. Therefore, legal inadequacy does not moderate the effect of competence trust on knowledge creation.

\subsection{Theoretical contributions}

This study contributes to literature in two ways. First, although scholars have cautioned that an overall measure of trust may not be able to provide a meaningful understanding of its roles in inter-firm relationships (Das and Teng, 2001), and that trust has both bright and dark sides (Molina-Morales et al., 2011; Villena et al., 2011), the positive and negative effects of competence and goodwill trust have seldom been explored empirically. This study is a step forward in understanding the distinctive effects of competence and goodwill trust on knowledge creation in $R \& D$ alliances. We find that the two types of trust affect knowledge creation through different mechanisms, contributing to literature by resolving the inconsistent findings regarding the roles of trust in inter-organizational knowledge management (Villena et al., 2011; Zhou et al., 2014). The curvilinear relationship between goodwill trust and knowledge creation indicates that the gains of investments in goodwill trust might be quite limited after it exceeds a threshold, enriching current knowledge about the effectiveness of inter-firm trust (Molina-Morales et al., 2011). This study thus provides a more nuanced understanding and a holistic picture on how to adjust investments in inter-firm relationships to fully reap the benefits of trust on knowledge creation.

Second, despite the widespread recognition of the importance of trust in promoting knowledge creation in partnerships, the influences of institutional parameters in shaping its roles remain underexplored. The study adopts a contingent view of alliance knowledge management by investigating the moderating effects of legal inadequacy. It represents an initial attempt to examine how the effects of interfirm trust are influenced by the legal environment (Cai et al., 2010; Hemmert et al., 2016). We contribute to literature by providing empirical evidence that inter-firm trust is not universal in its ability to promote knowledge creation: the effectiveness of goodwill trust is contingent upon the legal context of a R\&D alliance, whereas that of 
competence trust is not. Therefore, competence trust is a good substitute for formal governance mechanisms whereas relying on goodwill trust to manage R\&D alliances may impede knowledge creation under weak legal systems (Li et al., 2010; Sheng et al., 2013). Such findings provide a possible explanation for why Chinese firms can create knowledge and innovate without sufficient legal protection and deepen current understandings about the relationships between inter-firm trust and knowledge management (Kuo, 2013; Zhou et al., 2014).

\subsection{Managerial implications}

This study can provide guidelines for firms on how to improve knowledge creation and manage partnerships in China. We suggest managers rely on both competence and goodwill trust to manage R\&D alliances for knowledge creation. In addition, they must distinguish between competence and goodwill trust and understand their distinctive roles in promoting knowledge creation. In particular, when building R\&D alliances, managers can focus on the professionalism of partners, the usefulness of their advices, and their performance. Trusting partners with such characteristics enables firms to create new technological, product, and market knowledge. For the partners that have made sacrifices and are concerned with the firms' welfare and success, developing a trust-based relationship is advisable. However, managers should be warned that trusting those partners blindly may lead to opportunism or unintended spillovers in R\&D alliances, which hinder knowledge creation. Hence, managers should be cautious about the negative effect of goodwill trust, and regularly monitor the collaboration and evaluate R\&D alliances' performance to establish an optimal level of goodwill trust. Moreover, when firms face underdeveloped legal environments, managers can rely on competence trust to manage $R \& D$ alliances as its effectiveness is not affected by the quality of legal systems. In contrast, managers should understand that goodwill trust is a doubleedged sword. We suggest managers only use moderate levels of goodwill trust to manage R\&D alliances when legal inadequacy is high because high levels of goodwill trust may hinder knowledge creation.

\subsection{Limitations and future research directions}

This study has limitations that open up avenues for future research. First, the results are based on R\&D alliances in China. A useful extension will be to replicate this study in other countries with different institutional, cultural, and business environments to generalize the findings. Second, researchers argue that inter-firm 
trust also influences knowledge acquisition and transfer in partnerships (Zahra and George, 2002; Kuo et al., 2013; Zhou et al., 2014). Exploring how goodwill and competence trust affects knowledge acquisition and the relationships between knowledge acquisition and creation are interesting research topics. Third, besides trust, power, which is also a multidimensional concept, may also influence knowledge creation in R\&D alliances (Ireland and Webb, 2007). Future research may explore how different kinds of trust and power jointly affect knowledge management.

\section{References}

Aiken, L.S., and West, S.G. (1991), Multiple regression: Testing and interpreting interactions, Sage Publishing, Thousand Oaks.

Ang, Y. Y., and Jia, N. (2014), "Perverse complementarity: Political connections and the use of courts among private firms in China", The Journal of Politics, Vol.76, No.2, pp.318-332.

Cai, S., Jun M., and Yang, Z. (2010), "Implementing supply chain information integration in China: The role of institutional forces and trust", Journal of Operations Management, Vol.28, No.8, pp.257-268.

Connelly, B. L., Crook, T. R., Combs, J. G., Ketchen, D. J., and Aguinis, H. (2015), "Competence- and integrity-based trust in interorganizational relationships: Which matters more?", Journal of Management, DOI: $10.1177 / 0149206315596813$.

Das, T. K., and Teng, B. S. (2001), “Trust, control, and risk in strategic alliances: An integrated framework", Organization Studies, Vol.22, No.2, pp.251-283.

Doney, P.M., Cannon, J.P., and Mullen, M.R. (1998), "Uncerstanding the influence of national culture on the development of trust", Academy of Management Review, Vol.23, No.3, pp.601-620.

Faems, D., Janssens, M., Madhok A., and van Looy, B. (2008), "Toward an integrative perspective on alliance governance: Connecting contract design, trust dynamics, and contract application”, Academy of Management Journal, Vol.51, No.6, pp.1053-1078.

Fornell, C., and Larcker, D.F. (1981), "Evaluating structural equation models with unobservable variables and measurement error", Journal of Marketing Research, Vol.18, No.1, pp.39-50.

Grant, R.M. (1996), “Toward a knowledge-based view of the firm", Strategic 
Management Journal, Vol.26, No.17, pp.109-122 (Winter Special Issue).

Hemmert, M., Kim, D.S., Kim, J., and Cho, B. (2016), "Building the supplier's trust: Role of institutional forces and buyer firm practices", International Journal of Production Economics, Vol.180, No.1, pp.25-37.

Hofstede, G., Hofstede, G.J., and Minkov, M. (2010), Cultures and organizations: Software of the mind: Intercutural cooperation and its importance for survival, McGraw-Hill, New York.

Ireland, R.D., and Webb, J.W. (2007), “A multi-theorectic perspective on trust and power in strategic supply chains", Journal of Operations Management, Vol.25, No.2, pp.482-497.

Jeffries, F.L., and Reed, R. (2000), “Trust and adaptation in relational contracting”, Academy of Management Review, Vol.25, No.4, pp.873-882.

Jiang, X., Li, M., Gao, S., Bao, Y., and Jiang, F. (2013), "Managing knowledge leakage in strategic alliances: The effects of trust and formal contracts", Industrial Marketing Management, Vol.42, No.6, pp.983-991.

Kuo, T. (2013), "How expected benefit and trust influence knowledge sharing", Industrial Management \& Data Systems, Vol.113, No.4, pp.506-522.

Li, J.J., Poppo, L., and Zhou, K.Z. (2010), "Relational mechanisms, formal contracts, and local knowledge acquisition by international subsidiaries", Strategic Management Journal, Vol.31, No.4, pp.349-370.

Levin, D.Z., and Cross, R. (2004), "The strength of weak ties you can trust: The mediating role of trust in effective knowledge transfer", Management Science, Vol.50, No. 11, pp.1477-1490.

Lindell, M.K., and Whitney, D.J. (2001), “Accounting for common method variance in cross-sectional research designs", Journal of Applied Psychology, Vol.86, No.1, pp.114-121.

Lloria, M.B., and Peris-Ortiz, M. (2014), "Knowledge creation. The ongoing search for strategic renewal”, Industrial Management \& Data Systems, Vol.114, No.7, pp.1022-1035.

Lui, S.S., and Ngo, H.Y. (2004), "The role of trust and contractual safeguards on cooperation in non-equity alliances", Journal of Management, Vol.30, No.4, pp.471-485.

Lui, S.S., and Ngo, H.Y. (2012), "Drivers and outcomes of long-term orientation in cooperative relationships", British Journal of Management, Vol.23, No.4, 
pp.80-95.

Mayer, R.C., Davis, J. H., and Schoorman, F.D. (1995), “An integrative model of organizational trust", Academy of Management Review, Vol.20, No. 3, pp.709-734.

Molina-Morales, F.X., Martínez-Fernández, M.T., and Torlò, V.J. (2011), “The dark side of trust: The benefits, costs and optimal levels of trust for innovation performance", Long Range Planning, Vol.44, No.2, pp.118-133.

Nonaka, I. (1994), "A dynamic theory of organizational knowledge creation". Organization Science, Vol. 5, No. 1, pp.14-37.

Podsakoff, P.M., and Organ, D.W. (1986), "Self-reports in organizational research: problems and prospects", Journal of Management, Vol.12, pp.531-543.

Poppo, L., Zhou, K. Z., and Ryu, S. (2008), “Alternative origins to interorganizational trust: An interdependence perspective on the shadow of the past and the shadow of the future", Organization Science, Vol.19, No.1, pp.39-55.

Robson, M.J., Katsikeas, C.S., and Bello D.C. (2008), "Drivers and performance outcomes of trust in international strategic alliances: The role of organizational complexity", Organization Science, Vol.19, No. 4, pp.647-665.

Ramirez, A.M., Morales, V.J.,G., and Aranda, D.A. (2012), "Knowledge creation and flexibility of distribution of information", Industrial Management \& Data Systems, Vol. 112, No. 2, pp. 166-185.

Samaddar, S., and Kadiyala, S. S. (2006), "An analysis of interorganizational resource sharing decisions in collaborative knowledge creation", European Journal of Operational Research, Vol. 170, No.1, pp. 192-210.

Schilke, O., and Goerzen, A. (2010), "Alliance management capability: an investigation of the construct and its measurement", Journal of Management, Vol.36, No.5, pp.1192-1219.

Schoorman, F.D., Mayer, R.C., and Davis, J.H. (2007), “An integrative model of organizational trust: Past, present, and future", Academy Management Journal, Vol.32, No.2, pp.344-354.

Sheng, S., Zhou, K., and Lessassy, L. (2013), "NPD speed vs. innovativeness: The contingent impact of institutional and market environments", Journal of Business Research, Vol.66, No.11, pp.2355-2362.

Shu, C., Page, A.L., Gao S., and Jiang, X. (2012), "Managerial ties and firm innovation: Is knowledge creation a missing link?" Journal of Product 
Innovation Management, Vol.29, No.1, pp.125-143.

Smith, K.G., Collins, C.J., and Clark, K.D. (2005), "Existing knowledge, knowledge creation capability, and the rate of new product introduction in hightechnology firms", Academy of Management Journal, Vol.48, No.2, pp.346357.

Un, C.A., and Asakawa, K. (2015), "Types of R\&D collaborations and process innovation: The benefit of collaborating upstream in the knowledge chain", Journal of Product Innovation Management, Vol.32, No.1, pp.138-153.

Villena, V.H., Revilla, E., and Choi, T.Y. (2011), “The dark side of buyer-supplier relationships: A social capital perspective", Journal of Operations Management, Vol.29, No.6, pp.561-576.

Wang, L., Yeung, J.H.Y., and Zhang, M. (2011), “The impact of trust and contract on innovation performance: The moderating role of environmental uncertainty", International Journal of Production Economics, Vol.134, No.1, pp.114-122.

Yeung, J.H.Y., Selen, W., Zhang, M., and Huo, B. (2009), “The effects of trust and coercive power on supplier integration", International Journal of Production Economics, Vol.120, No.1, pp.66-78.

Zahra, S.A., and George, G. (2002), "Absorptive capacity: A review, reconceptualization, and extension", Academy of Management Review, Vol.27, No.1, pp.185-203.

Zhou, K.Z., and Poppo, L. (2010), "Exchange hazards, relational reliability, and contracts in China: The contingent role of legal enforceability", Journal of International Business Studies, Vol.41, No.5, pp.861-881.

Zhou, K.Z., Zhang, Q, Sheng, S., Xie E., and Bao, Y. (2014), “Are relational ties always good for knowledge acquisition? Buyer-supplier exchanges in China”, Journal of Operations Management, Vol.32, No.1, pp.88-98.

Zhang, M., Zhao, X., Voss, C., and Zhu, G. (2016), "Innovating through services, cocreation and supplier integration: Cases from China", International Journal of Production Economics, Vol.171, pp.289-300.

Zhang, S., Wang, Z., Zhao, X., and Zhang, M. (2017), "Effects of institutional support on innovation and performance: Roles of dysfunctional competition", Industrial Management \& Data Systems, Vol. 117, No. 1., pp. 50-67. 
Appendix Constructs and items

\section{Construct}

Loadings

Behavioral uncertainty $(\mathrm{CA}=.73 ; \mathrm{CR}=.85 ; \mathrm{AVE}=.65)$

It is difficult to measure this partner's performance.

Evaluating the performance of this partner requires extensive $\quad .75$ inspection.

It is difficult to evaluate whether this partner follows contracts.

Prior ties $(\mathrm{CA}=.86 ; \mathrm{CR}=.90 ; \mathrm{AVE}=.70)$

Before we ally with the partner,

we have a lot of interactions with its clients.

we have close relationships with its clients. $\quad .91$

we have partnerships with its clients. $\quad .90$

we have a good understanding with each other. $\quad .70$

Long-term orientation $(\mathrm{CA}=.91 ; \mathrm{CR}=.94 ; \mathrm{AVE}=.74)$

We expect this partner to be working with us for a long time. $\quad .76$

We will automatically renew the contract with this partner. $\quad .90$

We focus on long-term goals in this partnership. $\quad .87$

Maintaining a long-term relationship with this partner is important $\quad .88$

to us.

We believe that over the long run the relationship with this partner $\quad .89$ will be profitable.

\section{Legal inadequacy $(\mathrm{CA}=.81 ; \mathrm{CR}=.88 ; \mathrm{AVE}=.64)$}

It is difficult for the legal system to protect the interests for all .83

partners.

"Rule of man" is more common than "rule of law" in business field. $\quad .81$

The legal system (e.g., intellectual property laws) is very weak. $\quad .84$

The decisions made by the judicial system are difficult to be .71

smoothly executed.

Goodwill trust $(\mathrm{CA}=.80 ; \mathrm{CR}=.88 ; \mathrm{AVE}=.72)$

This partner is very concerned about our welfare. $\quad .80$

This partner is very concerned about our success. $\quad .88$

The partner will help us when we are in trouble. $\quad .87$

Competence trust $(\mathrm{CA}=.83 ; \mathrm{CR}=.89 ; \mathrm{AVE}=.67)$

This partner has no problems in answering our questions.

This partner is very professional about the work it does. $\quad .84$

The advice provided by this partner is always helpful. $\quad .82$

$\begin{array}{ll}\text { This partner has the ability to meet our needs. } & .80\end{array}$

Knowledge creation $(\mathrm{CA}=.84 ; \mathrm{CR}=.90 ; \mathrm{AVE}=.76)$

By allying with the $R \& D$ partner,

we develop new technological knowledge successfully. $\quad .79$

we develop new product knowledge successfully. $\quad .92$ 
we develop new market knowledge successfully.

Notes: $\mathrm{CA}=$ Cronbach's alpha; $\mathrm{CR}=$ composite reliability; $\mathrm{AVE}=$ average variance extracted. 